\title{
Lower Back Pain and Forearm Tendinitis Linked to Irritation of Oral Mucosa by Teeth
}

\author{
Sanae Miyaji \\ Ohana Dental Clinic Kannai, Yokohama, Japan \\ Email: sanae.miyaji@gmail.com
}

How to cite this paper: Miyaji, S. (2020) Lower Back Pain and Forearm Tendinitis Linked to Irritation of Oral Mucosa by Teeth. Case Reports in Clinical Medicine, 9, 295-302.

https://doi.org/10.4236/crcm.2020.99042

Received: August 16, 2020

Accepted: September 18, 2020

Published: September 21, 2020

Copyright $\odot 2020$ by author(s) and Scientific Research Publishing Inc. This work is licensed under the Creative Commons Attribution International License (CC BY 4.0).

http://creativecommons.org/licenses/by/4.0/

(c) (i) Open Access

\begin{abstract}
We present a case of a woman with refractory lower back pain and forearm tendinitis, which improved dramatically after morphological modification of natural teeth. The subject was a 35-year-old Japanese woman, who was suffering from lower back pain when bending forward and she had severe pain from her right thumb to her wrist. These symptoms were not improved by massage and orthopedic treatment. On the other hand, once modifying the morphology of natural teeth, those symptoms improved dramatically. No side effects were observed, and the prognosis was good. Our observation suggested a close relationship between the oral situation and remote musculoskeletal conditions, and further multidisciplinary studies are needed to clarify the mechanisms.
\end{abstract}

\section{Keywords}

Lower Back Pain, Forearm Tendinitis, Dental Treatment, Systemic Symptoms, The Bi-Digital O-Ring Test

\section{Introduction}

There are many reports that showed the relationship between dental and systemic or remote conditions. In particular, the effects of biting situation [1] [2] [3], jaw condition [4], mandibular conditions [5] [6] [7] [8], and focal infection [9] [10] have been investigated, recently, an association between lower back pain and harmful stimulation of oral mucosa by natural teeth has been reported [11]. Moreover, Fujii has reported on the relationship between electromagnetic waves and systemic conditions affecting the body [12]-[20] and intractable dermatitis owing to dental metal [21] [22]. However, to the author's knowledge, the relationship between tooth form and forearm tendinitis has not been reported so far. Here we report a case of a woman with lower back pain and forearm ten- 
dinitis related to pathological stimulation of the labial and buccal mucosa by teeth.

\section{A Case Presentation}

The subject was a 35-year-old Japanese woman, who worked as a hairdresser. Her chief complaint was lower back pain when bending forward and she had severe pain from her right thumb to her wrist and she couldn't even grasp scissors due to pain.

In the meantime, it became difficult to raise her right arms, and she felt numb from her right forearm to upper arm.

She was also feeling right side tension from the back of her neck to shoulder.

The subject had suffered from back pain for more than 10 years and went to massage, but the symptoms did not improve. She had felt pain and numbness of her right forearm for 16 months. She visited an orthopedic specialist who diagnosed right forearm tendinitis prescribed massage without any medications but this was not effective.

Local examination of the oral cavity showed a missing crown of the left upper second molar and a missing right second molar (Figure 1). Her biting situation seemed normal.

\section{Treatment for lower back pain}

While feeling no pain when bending backward, forward bending caused severe pain at the lumbar spine. Subsequently, the range of motion of the lumbar spine was restricted as she could bend forward only 45 degrees (Figure 2). When the Bi-Digital O-Ring Test was performed [23] [24], her O-Ring opened with opening her mouth (Figure 3), which has led to suspect that there was a cause of her lumber problem in the oral cavity. When the examiner put the finger on the labial side of the lower left central incisor, her O-Ring opened. The labial inclination of the lower left central incisor was apparently giving unfavorable stimulation to the labial mucosa, and therefore, the protrusion on the labial side of it was smoothened (Figure 4). This treatment was given in author's dental clinic 18 times over a period of 5 months. After this treatment, her back condition improved, but she still felt a small lower back pain. When pushing the upper right second molar from the buccal skin, her O-Ring opened (Figure 5), therefore, buccal surface of this tooth was smoothed. Although she could not bend forward enough due to severe back pain before the treatment (Figure 2), she had no pain after the treatment and she could bend 80 degrees forward (Figure 6). No side effects were observed, and this therapeutic effect persisted for at least 3 months despite not prosthesis of the missing teeth.

\section{Treatment for tendinitis}

When raising her upper arm by 135 degrees, she felt pain and numbness in the forearm (Figure 7). Pain increased when the examiner pushed her upper right first premolar with a finger from buccal skin. It seemed that the bumps on the buccal side of the tooth caused bad stimulation of the buccal mucosa. Therefore, 


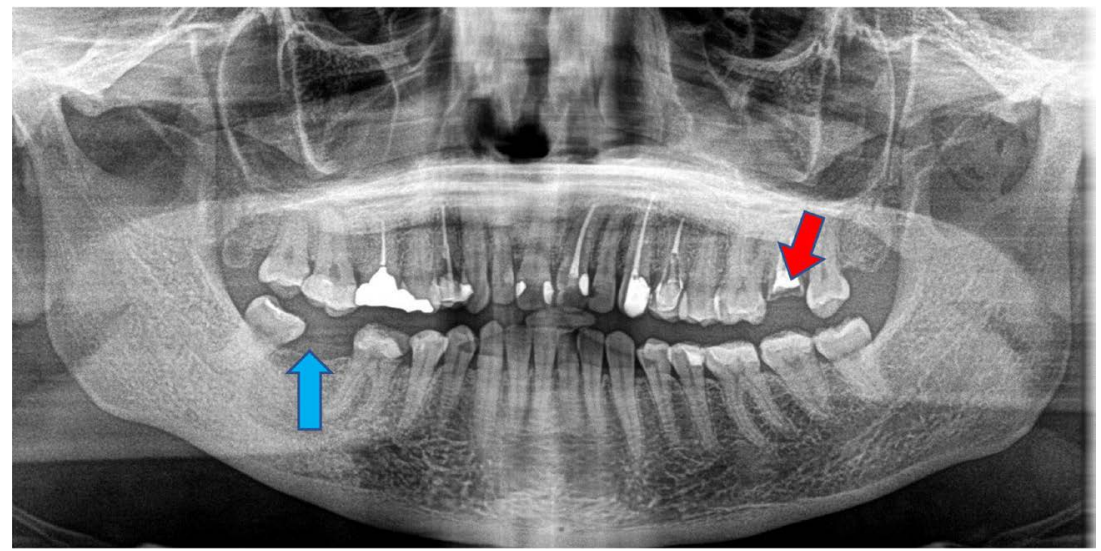

Figure 1. Panoramic X-ray image. A crown of upper left second molar (red arrow) and lower right second molar (blue arrow) were missing.

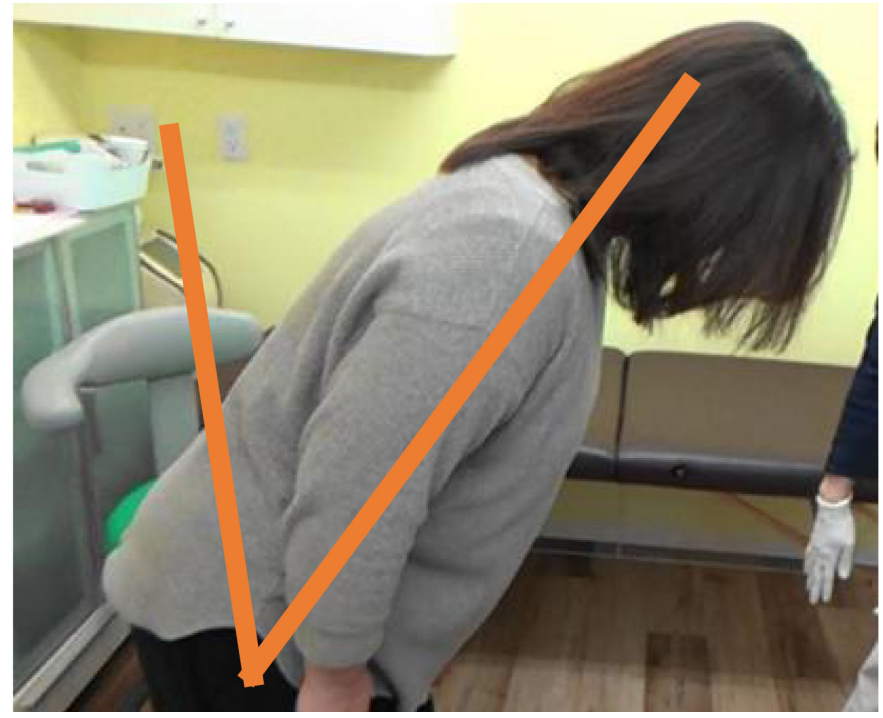

Figure 2. She could bend forwards only 45 degrees due to pain before treatment.

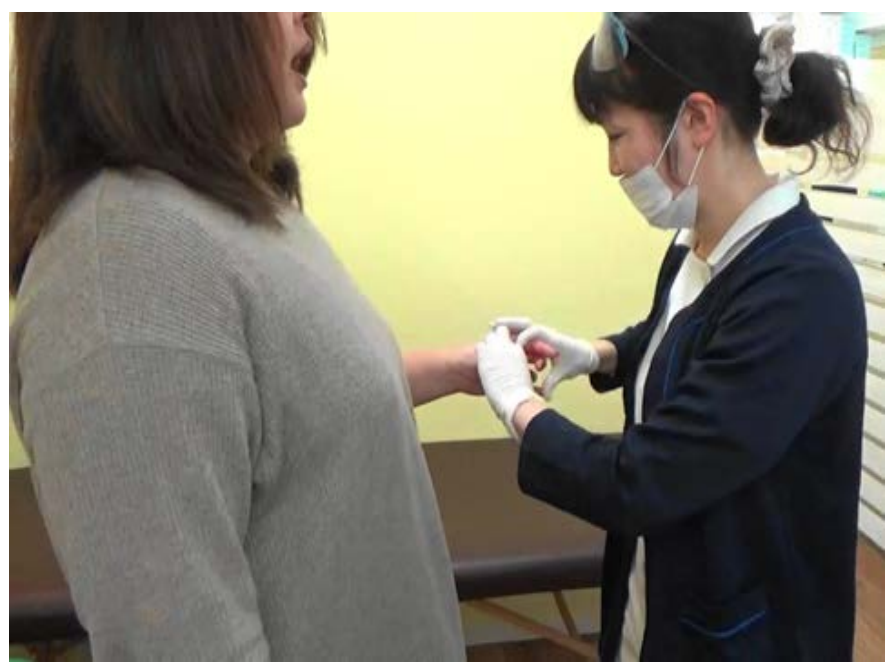

Figure 3. The Bi-Digital O-Ring test was performed. Her O-Ring opened when opening her mouth. 


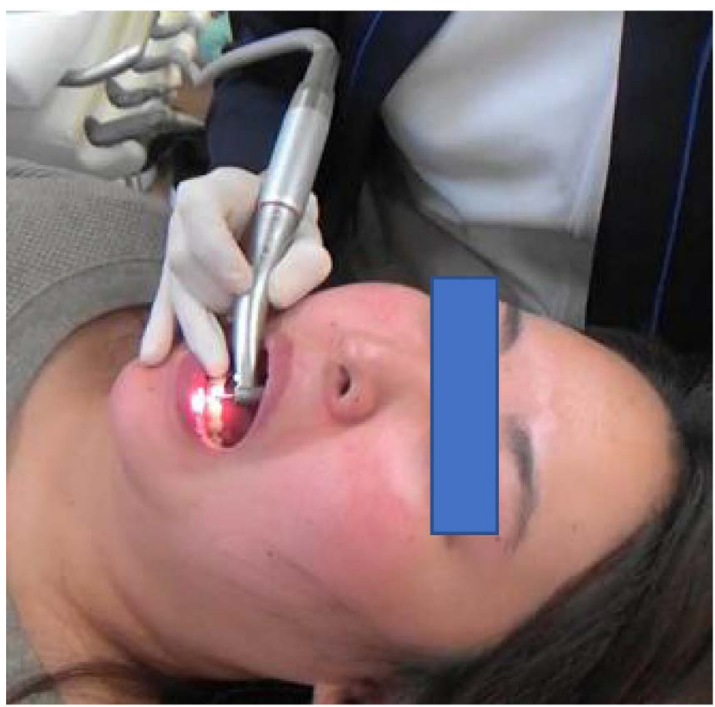

Figure 4. The protrusion on the labial side of left lower central incisor was smoothed.

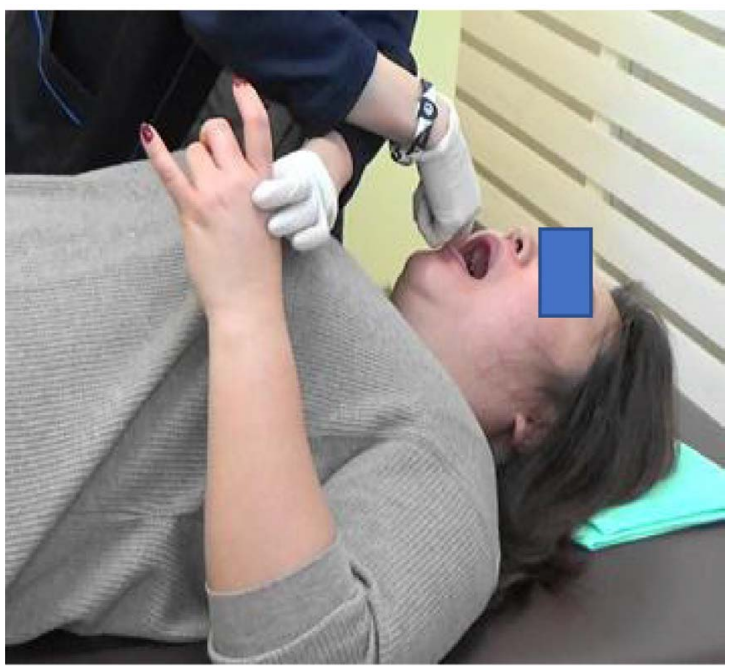

Figure 5. When pushing the upper right second molar from the buccal skin, her O-Ring opened.

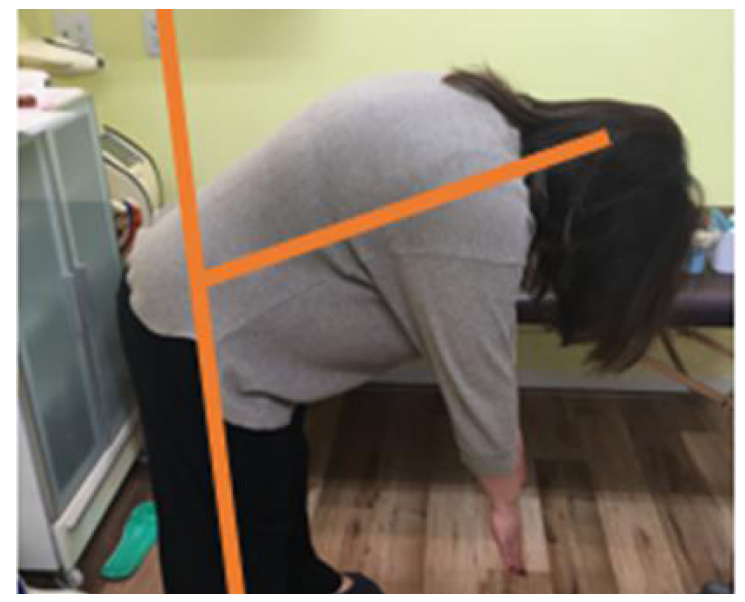

Figure 6. She could bend forward 80 degrees without pain after the treatment. 


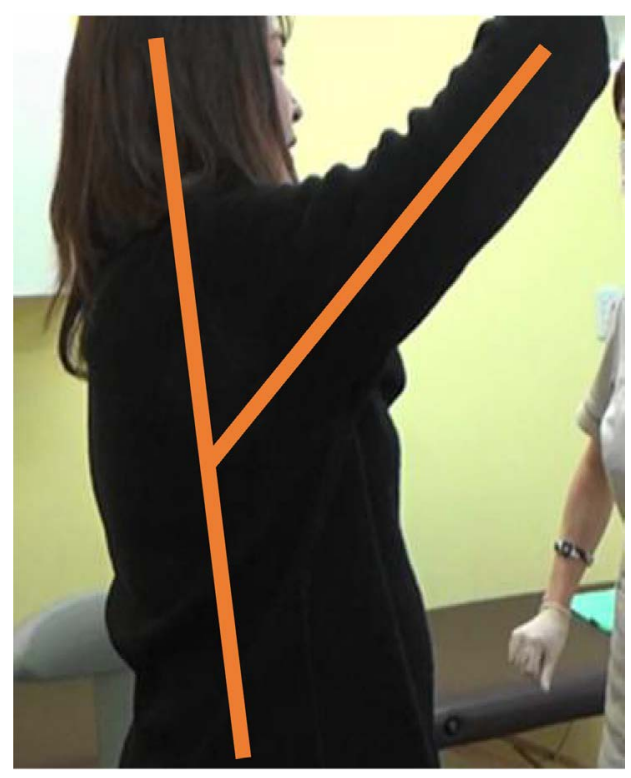

Figure 7. When raising her right arm by 135 degrees from her right shoulder, she felt pain and numbness in her forearm before treatment.

the buccal surface of the tooth was smoothened. This treatment was given in author's dental clinic10 times over a period of 9 months. After the treatment, she could raise her hands by 160 degrees without pain or numbness after the treatment (Figure 8) and the feeling of tension from the back of the neck to her shoulder improved.

This therapeutic effect persisted for at least 3 months despite not prosthesis of the missing teeth and no side effects were observed.

\section{Discussion}

There are many reports on the relationship between dental conditions and body conditions [1]-[22]. We presented a case which suggested that unfavorable stimulation of the mucous membrane by teeth surface may lead to distant effects on the body.

In this case, labial surface of the incisor of the lower jaw likely gave harmful stimulation to the labial mucosa of the lower lip may cause back pain. The upper right second molar stimulated the buccal mucosa, and it may have also contributed to back pain. Harmful stimulation of the buccal mucosa by the upper right first premolar might have caused her arm pain.

Forearm tendonitis is inflammation of the tendons of the forearm. The symptoms of it include severe pain when attempting to use the wrist, elbow, or forearm and numbness in the wrist, hands, fingers, or elbow, etc. The treatments of it include RICE (Rest, Ice, Compression, Elevation) therapy, medication (anti-inflammatory and pain medication, anesthetic medication, etc.) stretches, massage therapy, etc. [25]. However, dental treatment has not been reported.

The results of this treatment suggested that poor alignment and abnormal size or shape of teeth may cause irritation of the labial and buccal mucosa, resulting 


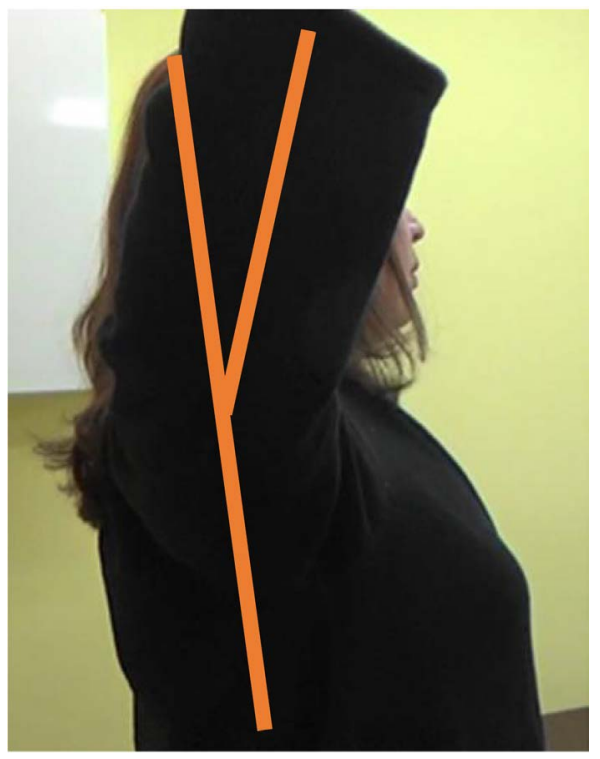

Figure 8. She could raise her right arm by 160 degrees without pain or numbness after the treatment.

in distant body issues, however, the underlying reason why this treatment was so dramatically successful remains unclear. Therefore, more investigation is needed. It is hypothesized that changing signals stimulate the brain via the trigeminal nerve which exists around oral area and it is the largest of the twelve cranial nerves. Indeed, it has been reported that the mouth exerts a strong influence on the brain [9] [26].

When opening and closing the mouth, in order to avoid bad stimuli, the mandibular may be displaced and cervical spine and lumbar spine are also distorted. The Bi-Digital O-ring Test was useful to lead clinical reasoning in this case [23] [24]. However, to clarify the exact mechanism, more multidisciplinary investigation is needed. These treatments were performed by a dentist, therefore, local physiologic tests are not possible. Therefore, cooperation with medical departments is important.

\section{Conclusion}

We showed that correcting the morphology and smoothing the rough surfaces of the teeth may improve lower back pain and forearm tendinitis that seemed to be an occupational disease in a beautician. Indeed, it was considered that abnormal stimulation of the labial and buccal mucosa by teeth may cause distant musculoskeletal symptoms, possibly due to strong effects of the mouth on the brain via trigeminal nerve. In the future, collaborative studies between dental and medical researchers will be mandatory to investigate the mechanism behind these peculiar relationships.

\section{Acknowledgements}

This patient agrees for her case to be reported. 


\section{Conflicts of Interest}

The author declares no conflicts of interest regarding the publication of this paper.

\section{References}

[1] Fujii, Y. (2015) Orthodontic Treatment to Improve Hip Joint Mobility and Balance. Journal of Dentistry, 3, 29-32. https://doi.org/10.12974/2311-8695.2015.03.01.5

[2] Karppinen, K., Eklund, S., Suoninen, E., Eskelin, M. and Kirveskari, P. (1999) Adjustment of Dental Occlusion in Treatment of Chronic Cervicobrachial Pain and Headache. Journal of Oral Rehabilitation, 26, 715-721. https://doi.org/10.1046/j.1365-2842.1999.00448.x

[3] Fujii, Y. (2019) Evaluation of a Mouthguard Customized Using the Occlusal Position during Maximal Grip Strength to Improve Sports Performance. A Case Report. Case Reports in Clinical Medicine, 8, 147-151. https://doi.org/10.4236/crcm.2019.86017

[4] Bracco, P., Deregibus, A. and Piscetta, R. (2004) Effects of Different Jaw Relations on Postural Stability in Human Subjects. Neuroscience Letters, 356, 228-230. https://doi.org/10.1016/j.neulet.2003.11.055

[5] Watanabe, E.K., Yatani, H., Kuboki, T., et al. (1998) The Relationship Between Signs and Symptoms of Temporomandibular Disorders and Bilateral Occlusal Contact Patterns during Lateral Excursions. Journal of Oral Rehabilitation, 25, 409-415. https://doi.org/10.1046/j.1365-2842.1998.00262.x

[6] Kobayashi, M., Yabushita, T., Zeredo, J.L., Toda, K. and Soma, K. (2007) Splenius Muscle Activities Induced by Temporomandibular Joint Stimulation in Rats. Brain Research Bulleti, 72, 44-48. https://doi.org/10.1016/j.brainresbull.2006.10.031

[7] Matsumoto, M.A.N., Matsumoto, W. and Bolognese, A.M. (2002) Study of the Signs and Symptoms of Temporomandibular Dysfunction in Individuals with Normal Occlusion and Malocclusion. The Journal of Craniomandibular \& Sleep Practice, 20, 274-281.

[8] Ciancaglini, R., Gherlone, E.F., Redaelli, S. and Radaelli, G. (2002) The Distribution of Occlusal Contacts in the Intercuspal Position and Temporomandibular Disorder. Journal of Oral Rehabilitation, 29, 1082-1090. https://doi.org/10.1046/j.1365-2842.2002.00941.x

[9] Fujii, Y. (2020) Two Cases of Parkinson's Disease for Which Dental Treatment Was Effective. Advances in Parkinson's Disease, 9, 13-19. https://doi.org/10.4236/apd.2020.92002

[10] Tanaka, T., Satoh, T. and Yokozeki, H. (2009) Dental Infection Associated with Nummular Eczema as an Overlooked Focal Infection. The Journal of Dermatology, 36, 462-465. https://doi.org/10.1111/j.1346-8138.2009.00677.x

[11] Fujii, Y. (2015) Dental Stimulation to the Buccal Mucous Membrane Cases Lumbago: A Report of Two Cases. Case Reports in Clinical Medicine, 4, 289-296. https://doi.org/10.4236/crcm.2015.48058

[12] Fujii, Y. (2007) The Dental Treatment That Used Environment of Electromagnetic Wave. Acupuncture and Electro-Therapeutics Research, 32, 291.

[13] Fujii, Y. (2009) The Consideration of the Electromagnetic Wave in Dental Material Substitution. Acupuncture and Electro-Therapeutics Research, 34, 89.

[14] Fujii, Y. (2012) Do Dental Implants Cause Scoliosis? Personalized Medicine Un- 
iverse, 1, 79-80. https://doi.org/10.1016/j.pmu.2012.05.012

[15] Fujii, Y. (2014) Gold Alloy Dental Inlay for Preventing Involuntary Body Movements Caused by Electromagnetic Waves Emitted by a Cell Phone. Open Journal of Antennas and Propagation, 2, 37-43. https://doi.org/10.4236/ojapr.2014.24005

[16] Fujii, Y. (2014) Sense of Balance Disorder Caused by Electromagnetic Waves Collected by a Dental Implant. Acupuncture and Electro-Therapeutics Research, 39, 379.

[17] Fujii, Y. (2014) Sensation of Balance Dysregulation Caused/Aggravated by a Collection of Electromagnetic Waves in a Dental Implant. Open Journal of Antennas and Propagation, 2, 29-35. https://doi.org/10.4236/ojapr.2014.23004

[18] Fujii, Y. (2015) Dental Treatment for Dizziness and Joint Mobility Disorder Caused by Harmful Electromagnetic Waves. Open Journal of Antennas and Propagation, 3, 1-7. https://doi.org/10.4236/ojapr.2015.31001

[19] Fujii, Y. (2015) Electromagnetic Waves Collected by a Dental Amalgam Filling Induced. Balance Dysregulation and Dizziness over a Period Exceeding 10 Years. Open Journal of Stomatology, 5, 235-242. https://doi.org/10.4236/ojst.2015.510029

[20] Fujii, Y. (2018) Hip Joint Pain Caused by Electromagnetic Waves Following an Operation for a Complex Humerus Fracture. Case Reports in Clinical Medicine, 7, 225-231. https://doi.org/10.4236/crcm.2018.73020

[21] Fujii, Y. (2014) A Case of Non-Allergenic Intractable Dermatitis Likely Caused by Mercury in Dental Amalgam. The Journal of Dentist, 2, 63-66.

https://doi.org/10.12974/2311-8695.2014.02.02.4

[22] Fujii, Y. (2017) Severe Dermatitis Might Be Caused by a Cross-Reaction Between Nickel and Palladium and Dental Amalgam Resolved Following Removal of Dental Restoration. Clinical Case Reports, 5, 795-800. https://doi.org/10.1002/ccr3.938

[23] Omura, Y. (1993) Bi-Digital O-Ring Test for Imaging and Diagnosis of Internal Organs of a Patient. US Patent No. 5188107. http://academic.reed.edu/economics/parker/f11/354/pat/o-ring.pdf

[24] Bi-Digital O-Ring Test (BDORT). http://bdort.org/

[25] Search Healthline What Is Forearm Tendonitis, and How's It Treated? https://www.healthline.com/health/forearm-tendonitis\#symptoms

[26] Fujii, Y. (2016) Two Cases of Severe Dementia Showing Dramatic Improvement after Denture Placement. Advances in Alzheimer's Disease, 5, 46-52. https://doi.org/10.4236/aad.2016.52004 